\title{
Topic Study Group No. 37: Mathematics Curriculum Development
}

\author{
Anita Rampal, Zalman Usiskin, Andreas Büchter, Jeremy Hodgen \\ and Iman Osta
}

\section{The Programme}

- Christian Hirsch. Print and digital curriculum design in the U.S.: The case of 'Transition to college mathematics and statistics'.

- Jerry Lipka. The emergence of the 'center of everything': Insiders and outsiders working together developing mathematics curricula from indigenous knowledge.

- Mark Prendergast, Cormac Breen, Michael Carr \& Fiona Faulkner. Investigating third level lecturers' awareness of second level curriculum reform.

- Anita Rampal. What math for all? For and from life?

- Teresa Rojano \& Armando Solares. The mathematics curriculum design from an international perspective: methodological elements for a comparative analysis.

- Dawn Teuscher, Lisa Kasmer, Travis Olson, and Shannon Dingman. Isometries in new U.S. middle grades textbooks: How are isometries and congruence related?

- Vivien Townsend. The 'mastery' curriculum in England: A battle with authoritative discourses of ability and accountability.

- Zalman Usiskin. Paradigms of curriculum development in school mathematics.

- Yan Guorui \& Frederick K.S. Leung. A comparative case study of teachers' use of mathematics textbooks in Beijing and Hong Kong.

Co-chairs: Anita Rampal, Zalman Usiskin.

Team members: Andreas Büchter, Jeremy Hodgen, Iman Osta.

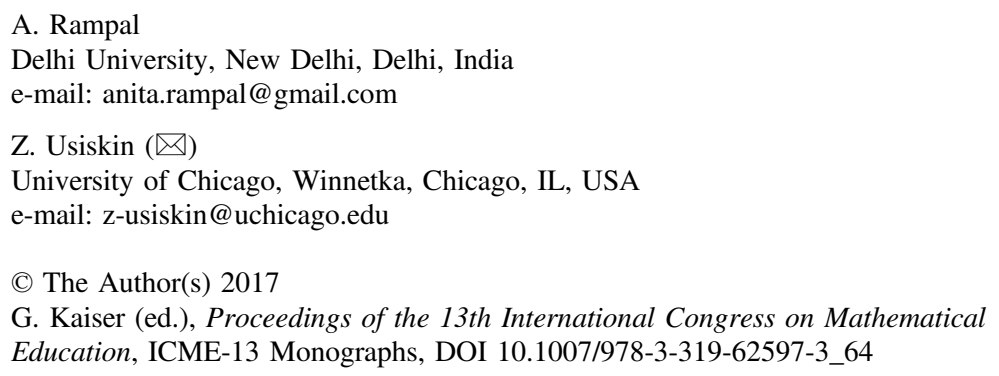




\section{Summary}

Curriculum concerns what we want students to learn, and when we want them to learn what we want them to learn; it is the heart of mathematics education. Curriculum development involves the processes that influence policy, the development of curriculum materials and pedagogical practices, and planning and implementation.

Other TSGs at ICME-13 discussed curriculum development in specific topic areas or with specific populations or age groups. TSG 37 sought papers of broader concern: the status of curriculum development in countries or regions; policies and influences shaping the development process; implementation, learnings, and future visions for curriculum development.

Usiskin identified five kinds of curriculum: ideal (intended), textbook (materials), implemented (taught), tested, and learned. The first four of these are created by people called policy makers, curriculum developers, teachers, and item writers, respectively. He offered three broad paradigms of curriculum development: traditional, test-influenced, and innovative. In the traditional paradigm, these five kinds are developed in the order shown above. In the test-influenced paradigm, tested curriculum specifications occur before materials are written. Discussions during TSG-37 sessions indicated that test-influenced curricula are exceedingly common throughout the world, with PISA and TIMSS results having particular impact in some countries.

For the innovative paradigm, Usiskin offered a sequence of events: (1) work by pioneers, the individuals who design the curriculum and assume a role comparable to policy makers in traditional curricula; (2) proselytizing of and by first users, who become apostles for the curriculum; (3) use by those disenchanted with the old curriculum; (4) acceptance by government agencies and teacher trainers if there is evidence of success; (5) if accepted; a forcing of the enchanted, those people who were content with the old curriculum and need persuasion or coersion to change. At this point, test creators take notice and, with enough support, the tests change to reflect the new ideas. But simultaneously, there can be pushback by those who question the need for the changes that the new curriculum embodies.

Rampal and Lipka each emphasized the need for curriculum to be developed from the cultures and lives of all students, rather than developing content from the hierarchy of mathematics. Rampal discussed efforts in the national primary mathematics curriculum of India to rethink mathematics, for and from life, for all children, through pedagogies of empathy that enable democratic participation. She noted the daunting challenges of curriculum development for public education in the 'gatekeeping' subjects of science and math in socially and culturally diverse poor countries, in the light of national pressures to reserve professional opportunities for the 'talented' privileged, and increasing global pressures for curriculum homogenization and standardization, tied to aggressive formulations of learning 
outcomes, with increasing transnational corporate interests in promoting 'low fee' private schools for the poor.

The curricular materials and textbooks developed by Rampal et al. follow a constructivist approach and also involve thematic issues of work, entrepreneurship, heritage, craft knowledge, history of monuments and pre-historic cave paintings, etc. using contexts that invoke and integrate concepts already learnt. In a similar vein, Lipka engaged the TSG participants in activities involving the "center of everything" from a curriculum he and individuals from the Yupiaq community in Alaska designed together. He noted that indigenous knowledge is rarely part of a core academic subject and that in the USA and elsewhere, indigenous people and their knowledge have been suppressed. His work uses indigenous knowledge to create an accessible curriculum for teaching the foundations of mathematical thinking for elementary school students. This work has included scholars and knowledge holders at Saami University, at the University of Greenland, and in Micronesia with Carolinian knowledge holders from Yap State and Chuuk who are associated with their respective Departments of Education. This work fits squarely into the role of ethnomathematics in mathematics curriculum.

Rojano presented a study to evaluate, from an international perspective, the current mathematics curriculum for compulsory education in Mexico. The Mexican curriculum was compared with those of the United Kingdom, Chile, and South Korea. Four influences on conceptions of school mathematics were noted: the international context of mathematics education; mathematics education research; the role of mathematics in the broader school curriculum; and distinctive traits in the quality of curriculum design. Differences were found concerning how school mathematics is conceived in the four curricula. Differences also exist in the presentation of the curriculum-e.g., how much detail, the presence or absence of discussions of relevance and of problem-solving. Notable in all four curricula was the lack of explicit references to research literature, as well as their inclusion of innovations in terms of content or teaching approaches (use of ICT or early algebra, for instance). However, all four programmes showed signs of the influence of education research. Suggestions are given for a redesign of the manner in which the Mexican curriculum is presented.

In England in 2014 a new national mathematics curriculum was introduced. This curriculum introduces some content in earlier grades than before and is accompanied by rhetoric identifying "mastery" as an overriding goal for all students - not just a few. Mastery is specified as mathematical fluency and conceptual understanding, and the ability to reason mathematically and solve problems. Townsend presented a case study of a primary school teacher (whose job entails teaching all subjects) who struggles with bringing all students to mastery, against longstanding beliefs that mastery is possible only for some students. Townsend concluded that teachers like this one "will be left to mediate tensions between adopting new ways of working alongside ingrained practices resulting from historical authoritative discourses." 
Prendergast reported on his study of the knowledge of tertiary mathematics lecturers about Project Maths, a recent change in the secondary mathematics course content, teaching, and assessment in Ireland. Most lecturers were aware that there was more emphasis on understanding, more mathematics in context, and more exploration and activities. Those aware of changes in assessment pointed out the fact that it is now more difficult to predict the kinds of questions. Yet in all these domains, the majority of the lecturers indicated they had made no change and did not plan to make any change.

Hirsch described the development of a new course, Transition to College Mathematics and Statistics designed for the last year of secondary school, primarily for college-intending students whose planned programs of study do not require calculus. The course is notable for the United States for including of concepts from algebra and functions, statistics and probability, discrete mathematics, and geometric visualization. These branches of mathematics are connected by the central themes of the course, modeling of our world and the nurturing of mathematical habits of mind. A suite of curriculum-embedded technological tools has been developed for the course. The course was developed with the aid of extensive field-testing and has been tested in a variety of settings in the past few years, and the testing suggests that students are able to solve more complex and more open-ended problems. In so doing, they seem to be more able to work in teams and assess their own work and the work of the team.

Teuscher compared the ideal curriculum as found in the U.S. Common Core State Standards in Mathematics (CCSSM) with the approach to isometries and congruence in six current middle school textbook series. Geometric transformations have only been universally found in books at this level since 2010. The researchers found that three series defined congruence without regard to isometries even though the CCSSM ask for a definition in terms of isometries. Very little work was done on properties of isometries, and errors were found in some of the materials with regard to the discussion of orientation. The researchers concluded that teachers need to be aware of these difficulties, but this is unlikely because so many teachers themselves have never previously encountered this content.

Guorui examined how two teachers in each of two schools in Beijing and Hong Kong utilized mathematics textbooks to develop the taught curriculum. The Pythagorean Theorem was chosen so as to have uniform content, though the teachers were purposely selected so that in each school one teacher had at least 18 years and the other had less than 5 years experience. The experienced teachers tended to go beyond the textbook more than the inexperienced. The researchers pointed out the variety of factors that influence textbook use beyond the textbook itself, including the education system, school policies and practices, and teacher personal traits, themselves all influenced by socio-cultural factors.

In all, the papers demonstrate the complexity of developing mathematics curriculum reflecting the broad range of desires and needs of mathematics in our world 
while simultaneously taking into account the correspondingly broad socio-cultural backgrounds of students and the variety of teachers and schools in any system. Animated discussion in each of the sessions and participants enriched the deliberations by relating some if these issues to participants' own specific contexts.

Open Access Except where otherwise noted, this chapter is licensed under a Creative Commons Attribution 4.0 International License. To view a copy of this license, visit http://creativecommons. org/licenses/by/4.0/.

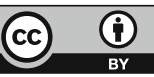

